\title{
Suppressed expression of genes involved in transcription and translation in in vitro compared with in vivo cultured bovine embryos
}

\author{
D Corcoran, T Fair, S Park, D Rizos, O V Patel ${ }^{1}$, G W Smith ${ }^{1}$, P M Coussens ${ }^{1}$, J J Ireland ${ }^{1}$, \\ M P Boland, A C O Evans and P Lonergan
}

School of Agriculture, Food Science and Veterinary Medicine and Centre for Integrative Biology, Conway Institute for Biomolecular and Biomedical Research, College of Life Sciences, University College Dublin, Belfield, Dublin 4, Ireland and ${ }^{1}$ Department of Animal Science and Center for Animal Functional Genomics Michigan State University, East Lansing, Michigan 48824, USA

Correspondence should be addressed to P Lonergan; Email: pat.lonergan@ucd.ie

\begin{abstract}
In vivo-derived bovine embryos are of higher quality than those derived in vitro. Many of the differences in quality can be related to culture environment-induced changes in mRNA abundance. The aim of this study was to identify a range of mRNA transcripts that are differentially expressed between bovine blastocysts derived from in vitro versus in vivo culture. Microarray (BOTL5) comparison between in vivo- and in vitro-cultured bovine blastocysts identified 384 genes and expressed sequence tags (ESTs) that were differentially expressed; $85 \%$ of these were down-regulated in in vitro cultured blastocysts, showing a much reduced overall level of mRNA expression in in vitro- compared with in vivo-cultured blastocysts. Relative expression of 16 out of $23(70 \%)$ differentially expressed genes (according to $P$ value) were verified in new pools of in vivo- and in vitrocultured blastocysts, using quantitative real-time PCR. Most (10 out of 16) are involved in transcription and translation events, suggesting that the reason why in vitro-derived embryos are of inferior quality compared with in vivo-derived embryos is due to a deficiency of the machinery associated with transcription and translation.

Reproduction (2006) 131 651-660
\end{abstract}

\section{Introduction}

It is estimated that fetal viability is only achieved in $30 \%$ of all human conceptions with the greatest loss (50\%) occurring prior to the first missed menses and during early stages of implantation (25\%) (Edmonds et al. 1982). Similarly, cattle experience relatively high rates of embryonic and early fetal mortality (about 40\%). Published estimates indicate a fertilization rate of $90 \%$ and an average calving rate of about $55 \%$, suggesting an embryonic/fetal mortality of about $35 \%$; it is estimated that $70-80 \%$ of the total embryonic loss occurs between days 8 and 16 after insemination (day 16 corresponding to the period of maternal recognition of pregnancy (reviewed by Peters 1996, Ball 1997, Sreenan et al. 2001).

The in vitro production of bovine embryos is essentially a three-step process involving in vitro oocyte maturation, in vitro fertilization and in vitro culture. Most of the differences in the quality of in vitro- compared with in vivo-derived embryos are due to the last step, the culture environment for post-fertilization early embryo development (Rizos et al. 2002b, 2002c, Lonergan et al. 2003a). It is during this time that the embryo switches from using genes and proteins derived from the maternal genome (in the oocyte) to those resulting from the newly activated embryonic genome (8-16 cell stage in cattle; Memili \& First 2000). It is well recognized that bovine embryos derived in vivo are of higher quality than those derived in vitro (Hasler et al. 1995). In vitro-produced blastocysts tend to have darker cytoplasm and lower buoyant density (Pollard \& Leibo 1994), due to their higher lipid content (Abd El Razek et al. 2000), a more fragile zona pellucida (Duby et al. 1997), reduced intracellular communication (Boni et al. 1999), differences in metabolism (Khurana \& Niemann 2000, Thompson 2000) and a higher incidence of chromosome abnormalities (Viuff et al. 1999, Lonergan et al. 2004). In addition, many differences have been reported at the ultrastructural level (Crosier et al. 2000, 2001, 2002, Fair et al. 2001, Rizos et al. 2002a), which reflect some of the differences noted above. 
Studies in bovine embryos indicate that many of the differences in quality of in vitro- and in vivo-derived blastocysts can be related to culture environment-induced changes in mRNA abundance. The post-fertilization embryo culture environment has a dramatic effect on the pattern of gene expression in embryos, which in turn has serious implications for the normality of blastocyst development (Lonergan et al. 2003a, Tesfaye et al. 2004). This is the case, not only when one compares in vitro and in vivo culture systems, but also comparing different in vitro culture systems (reviewed by Lonergan et al. 2003a, Wrenzycki et al. 2005).

The oviduct of the ewe has been shown by several authors to be a suitable environment for the development of bovine embryos from the zygote to blastocyst stage. Although not perfect, one advantage of this in vivo culture system is the ability to culture large numbers of embryos in a near in vivo environment and in a cost-effective manner. While the yield of blastocysts following such in vivo culture is not superior to that following culture in vitro, the quality of the blastocysts is significantly improved (Galli \& Lazzari 1996, Enright et al. 2000, Lazzari et al. 2002, Rizos et al. 2002c, 2003). Blastocysts produced in this way are similar to true in vivo embryos in terms of morphology (Fair et al. 2001), cryotolerance (Enright et al. 2000, Rizos et al. 2002a), mRNA expression pattern for select genes (Lazzari et al. 2002, Rizos et al. 2002c) and pregnancy rate following transfer (Lazzari et al. 2002).

Until recently, methods of analysis of differential gene expression in embryos were confined to the use of quantitative real-time PCR (Q-RT-PCR) using primers for specific candidate genes. Such gene-by-gene analysis provides too narrow a view of the potentially complex underlying regulatory networks involved in embryo pre-implantation development. Depending on the species availability, DNA microarray analyses provide a genome-wide perspective by profiling the expression of thousands of genes simultaneously. The aim of the present study was to use this technology to identify a range of mRNA transcripts that are differentially expressed between bovine blastocysts derived from in vitro versus in vivo culture.

\section{Materials and Methods}

Three experiments were performed. In experiment 1 , the effect of linear amplification on the relative levels of gene expression in two-cell embryos compared with blastocyststage embryos was analysed. Experiment 2 involved the use of microarrays as a discovery tool to identify potentially differentially expressed mRNA transcripts between blastocysts produced by in vivo or in vitro culture. In experiment 3, Q-RT-PCR was used to confirm differential expression of those transcripts identified in experiment 2 in a third set of embryos.

\section{Experiment 1}

In vitro embryo production (IVP)

Immature cumulus oocyte complexes (COCs) were obtained by aspirating surface-visible follicles from ovaries obtained from heifers at a local abattoir. The COCs were then matured and fertilized in vitro as previously described (Rizos et al. 2002C). At approximately $20 \mathrm{~h}$ post-insemination (hpi), presumptive zygotes were denuded by gentle vortexing and washed four times in PBS and twice in synthetic oviduct fluid medium (SOF). Zygotes were then cultured in SOF, supplemented with $10 \%(\mathrm{v} / \mathrm{v})$ fetal calf serum, for $24 \mathrm{~h}$ (to produce two-cell embryos) or for 7 days (to produce blastocyst-stage embryos). Embryos from three separate replicates (from different ovary collection days) were pooled to give a total of 50 two-cell embryos and 50 blastocysts. Samples were snap frozen in liquid nitrogen and stored at $-80^{\circ} \mathrm{C}$ until use.

\section{$R N A$ isolation and amplification}

Total RNA was extracted from pools of two-cell embryos and blastocysts using the PicoPure RNA Isolation Kit (catalogue number KIT0204; Arcturus, Mountain View, CA, USA) according to the manufacturer's instructions. Following extraction, the RNA samples were DNAse-treated (Stratagene, La Jolla, CA, USA) and first-strand cDNA was synthesized incorporating a T7 promoter according to the manufacturer's instructions. Using exogenous primers, double-stranded cDNA was synthesized and then purified using purification columns. A $3.5 \mu \mathrm{l}$ aliquot of unamplified CDNA was removed from both the two-cell and blastocyst samples for Q-RT-PCR analysis and stored at $-20^{\circ} \mathrm{C}$ until use. The remaining cDNA $(12.5 \mu \mathrm{l})$ was submitted to one round of amplification using the RiboAmp RNA Amplification Kit (catalogue number KIT0201; Arcturus), which linearly amplifies the mRNA fraction of total RNA using cDNA as template in a T7 RNA polymerase-catalysed amplification reaction. A $3.5 \mu \mathrm{l}$ aliquot of cDNA was taken following one round of amplification from both the two-cell and blastocyst-stage samples and stored at $-20^{\circ} \mathrm{C}$ until use in Q-RT-PCR. The remainder $(12.5 \mu \mathrm{l})$ was submitted to a second round of amplification and again a $3.5 \mu \mathrm{l}$ aliqout of the resulting cDNA was stored at $-20^{\circ} \mathrm{C}$ until use in Q-RT-PCR.

\section{Q-RT-PCR}

Q-RT-PCR reactions (MXP3000 Real-Time PCR System; Stratagene) were conducted in triplicate to contrast relative levels of transcripts for two selected genes, ferritin and $\beta$-actin, using bovine histone $\mathrm{H} 2 \mathrm{AZ}$ as a housekeeping gene (Jeong et al. 2005; Table 1). PCR was performed by adding a $4 \mu \mathrm{l}$ aliquot of each sample (each $3.5 \mu \mathrm{l}$ sample stored from the amplification reactions was diluted in $40 \mu \mathrm{l}$ sterile water) to the PCR mix containing gene specific primers and SYBR Green Master Mix (Brilliant Sybr Green QPCR Master Mix; Stratagene). The PCR protocol included 
Table 1 GenBank accession number and forward and reverse primer sequences of genes and ESTs for Q-RT-PCR.

\begin{tabular}{|c|c|c|c|}
\hline Accession number & Gene & Forward primer sequence & Reverse primer sequence \\
\hline AF540563 & Ferritin & GGGTGACCACATAACCAACC & AATATGCATGCACTGCCTTG \\
\hline AB098974 & $\beta$-Actin & TTGAACACGGCATCATCACT & GCATAGAGGGAGAGCACAGC \\
\hline X52318 & Histone $\mathrm{H} 2 \mathrm{AZ}$ & GGTAAGGCTGGGAAGGACTC & GATGCATTTCCTGCСАATTC \\
\hline BE588526 & Galactose-4'-epimerase (GALE) & CGACGGGAGGTACTGAATGT & ATGGCCTGGACCATCTGTAG \\
\hline CB461593 & Signal-induced proliferation-associated gene 1 (SIPA1) & AGGTGGGCATCTTGTACTGC & ACGTGGTGTAAAGGGAGTGC \\
\hline CN441852 & CCR4-NOT transcription complex, subunit 3 & GAGTTCTACCAGCGCCTGTC & GGTGAAGCCTTCCTTCTTCC \\
\hline NM_175802 & Guanine nucleotide-binding protein (GNB2LI) & GTGCTCTTCGAGGTCACTCC & CGGTTGTCAGAGGAGAAAGC \\
\hline AF509504 & DOT1-like protein (DOT1L) & AGTCTCGCGGTTGAGGTAGA & GCTGCAGTCССTGTTCAGTT \\
\hline NM_005171 & Activating transcription factor 1 (ATF1) & GTGGGGAAGTGGGTAGTGAA & AGCTGCCTGAACTGTGGAAC \\
\hline BF230159 & Elongation facor 1 gamma (EEF1G) & TGGATGCTCACTTGAAGACG & ACTGGGCCATTTTCTCACAG \\
\hline NM_174569 & Poly(A)-binding protein II (PABPN1) & GGAGGGAGGGTAGTGAAAGG & CTCCAGACCAGGCTACTTCG \\
\hline NM_019080 & NEDD 4 family interacting protein 2 (NDFIP2) & CAGAAACAGAGGCGGAAGAG & GTGTGTGGTGTTGGGTTTGA \\
\hline NM 174729 & Voltage-dependent anion channel 3 (VDAC3) & CTTCACGCAGAAGTGGAACA & ACСТTCAAAGGCCAACACAG \\
\hline BM25̄51556 & Heme-binding protein (HEBP1) & СTGGСTCTGAAGGGAAGTTG & АCTTCTGCACCGGGTATGAC \\
\hline NM 000160 & Homo sapiens glucagons receptor (GCGR) & AACTACTGCTGGCTGCTGGT & TCCAGCACTGAATGTTCTCG \\
\hline NM_015939 & BOTL0100009_G06 (9_G06) & TTATCAGTGCCCGCTTCTTT & GCTGAAACGGGAAGATGTGT \\
\hline BM252092 & BOTL0100003XC10R (3XC10R) & GTCCAGGTTCTGССTCACTC & TGGGTTAAGGAACCAGTGGA \\
\hline
\end{tabular}

an initial step of $95^{\circ} \mathrm{C}(10 \mathrm{~min})$, followed by 40 cycles of $95^{\circ} \mathrm{C}(30 \mathrm{~s}), 56-59^{\circ} \mathrm{C}(1 \mathrm{~min})$ and $72{ }^{\circ} \mathrm{C}(30 \mathrm{~s})$. At the completion of cycling, melting curve analysis was carried out to establish the specificity of the amplicons produced. Q-RT-PCR data ( $C_{\mathrm{t}}$ values) were analysed using the $2^{-\Delta \Delta C_{\mathrm{t}}}$ method (Livak \& Schmittgen 2001).

\section{Experiment 2}

\section{Blastocyst production}

Presumptive zygotes produced in vitro as described above were either cultured in vitro, in SOF, for 6 days or were cultured in vivo following surgical transfer to the ligated ewe oviduct (approximately 100 embryos per oviduct) for 6 days (Rizos et al. 2002c). At the end of culture, blastocysts from both groups were snap frozen in liquid nitrogen and stored at $-80^{\circ} \mathrm{C}$. All animal experiments were performed in accordance with Institutional Animal Care and Use Committee guidelines and in adherence with guidelines established in the Guide for Care and Use of Laboratory Animals as adopted and promulgated by the Society for the Study of Reproduction.

\section{RNA isolation and amplification}

Total RNA was extracted from eight groups of day 7 blastocysts (50 per group; 200 in vivo cultured, 200 in vitro cultured) and amplified as described above. The resulting aRNA was concentrated using alcohol precipitation and quantified using the Agilent 2100 Bioanalyzer (Agilent, Sandyford, Dublin, Ireland). The final concentration of aRNA was $2.25 \mu \mathrm{g} / \mu \mathrm{l}$.

\section{Microarray hybridization}

The cDNA microarrays (BOTL-5) used in this experiment contained 3888 total spots with 932 bovine EST clone inserts developed from a normalized bovine total leukocyte (BOTL) cDNA library and an additional
459 amplicons representing additional genes including cytokines, receptors, signal transduction molecules, transcription and growth factors, enzymes, cell cycle regulators and cellular components. We have previously used a predecessor of this array (BOTL-4) to identify genes involved in apoptosis and dominant follicle development during follicular waves in cattle (Evans et al. 2004). A list of genes represented on the BOTL microarrays and their sequences can be found at http://www.nbfgc.msu.edu under the 'links' section.

Cy3- and Cy5-labelled cDNA probes for use in dual colour microarray hybridizations were created using the Cyscribe Post-Labelling Kit RPN5660 (Amersham). Amino allyl-dUTP (AA-dUTP) was incorporated into the aRNA samples in a cDNA synthesis reaction, catalysed by CyScript reverse transcriptase according to the manufacturer's instructions. The cDNA was then purified from RNA strands and unincorporated nucleotides by ethanol precipitation. cDNA from blastocysts derived from in vivo or in vitro culture was differentially labelled using $\mathrm{N}$-hydroxsuccinimide (NHS)activated fluorescent Cy3 or Cy5 dyes (Amersham Pharmacia Ltd, Piscataway, NJ, USA). Fluorescent labelling of the cDNA was carried out according to the manufacturer's instructions and was achieved by CyDye NHS esters reacting with the amino allyl groups incorporated into the cDNA first-strand synthesis. Four replicates were carried out; each replicate was comprised of blastocysts derived from a different ovary collection date. In vivo-cultured blastocysts in replicates 1 and 2 were labelled with Cy3 fluorescent dye and in vitro-cultured blastocysts were labelled with Cy5 fluorescent dye. Blastocysts in replicates 3 and 4 were labelled in the opposite way.

Unincorporated CyDye molecules were removed using purification columns from Qiagen (Min Elute PCR Purification Kit, catalogue number 28004). The two samples within each replicate were combined (i.e. Cy3-labelled, in vitro-cultured sample combined with the Cy5-labelled, in vivo-cultured sample) and concentrated to $10 \mu \mathrm{l}$ using 
a microcon 30 spin concentrator (Millipore Corp., Bedford, MA, USA). Finally, hybridization buffer (SlideHyb-3, Ambion, TX, USA) was added to give a final volume of $100 \mu \mathrm{l}$.

The hybridization probes were added to the microarray slides, and hybridizations were conducted for $18 \mathrm{~h}$ in a commercial microarray hybridization station (HS 400 Tecan, Maennedorf, Switzerland) using a step-down hybridization protocol $\left(65^{\circ} \mathrm{C}\right.$ for $3 \mathrm{~h}, 55^{\circ} \mathrm{C}$ for $3 \mathrm{~h}, 50^{\circ} \mathrm{C}$ for $12 \mathrm{~h}$ ). Following hybridization, cDNA microarrays were washed within the hybridization station $\left(42-50^{\circ} \mathrm{C}\right)$, rinsed once in $2 \times$ saline sodium citrate and once in $\mathrm{ddH}_{2} \mathrm{O}$ and finally dried within the hybridization station. Slides were then scanned using an Axon Genepix 4000B scanner (Molecular Devices Corporation, Union City, CA, USA) and Genepix Pro 5.0 software (Molecular Devices Corporation) was used to process images, find spots, integrate the GAL (gene array list) file and finally to create reports of spot fluorescence intensities and local background fluorescence intensities.

\section{Microarray data analysis}

Data were analysed using three different approaches in order to generate a robust data set containing lists of genes/ESTs that were differentially expressed between the two groups of embryos being examined. In the first analysis, data from each replicate were normalized using a robust local regression technique (Cleveland \& Grosse 1991) using the LOESS (locally-weighted regression and smoothing scatter plots) procedure of SAS (version 8, SAS Institute Inc., Cary, NC, USA). Normalized data were then back transformed and the intensity for the blastocysts cultured in vitro was divided by the intensity for those cultured in vivo to give an expression ratio value. The likelihood that the relative expression ratios of the four replicates differed from one (i.e. the same) was determined using Student's $t$ test. In the second analysis, the procedure described above was repeated on data that were first background adjusted using Genepix Pro 5.0 software. Again, an expression ratio value was calculated and the likelihood that the values from the four replicates differed from one was determined using Student's $t$ test. In the third analysis, a global normalisation method was used where a log ratio value was calculated for Cy3 and Cy5 values adjusted for background fluorescence. These values within each microarray were normalized to the GAPDH housekeeping gene (as there were 76 GAPDH spots on the array) using a single correction factor across that array. The likelihood that the resulting expression ratio values for the replicates differed from one was determined using Student's $t$ test.

\section{Mapping of arrayed clones to gene ontology (GO) terms}

Arrayed clone sequences were matched to the nearest human and bovine homologs in RefSeq and UniProt by
BLAST searching. For RefSeq homology searches, an e-value threshold of $1 \times 10^{-30}$ was used for human matches and a more stringent e-value threshold of $1 \times 10^{-100}$ was used for bovine matches. For UniProt homology searches, an e-value threshold of $1 \times 10^{-30}$ was used for human searches and $1 \times 10^{-50}$ for bovine matches. The lower stringency thresholds used in establishing homology to human sequences reflect the evolutionary divergence between human and bovine gene sequences.

GO classifications for clones were obtained via Uniprot and EntrezGene. For UniProt, GO associations for the protein homologs of the arrayed clones were obtained directly from the UniProt database. For Entrezgene, the RefSeq homologs of the arrayed clones were mapped to EntrezGene accessions and from there to GO IDs using the associations in the files gene2refseq and gene2go obtained from the NCBI ftp site (ftp://ftp.ncbi.nlm.nih.gov/gene/ DATA/). Parent terms of each GO term were obtained by parsing the GO obo flat file (obtained from http://www. geneontology.org/ontology/gene_ontology.obo) using the perl GO parser distributed as part of the Bioperl package (http://bioperl.org). For every GO term linked to a clone on the array, the set of parent GO terms were added as new links to the clone. The generic GO slim ontology produced by Mundodi and Ireland was obtained from ftp://ftp. geneontology.org/pub/go/GO_slims/archived_GO_slims/ge neric.0208. Terms in the full GO were mapped to terms in the slim ontology using the map2slim.pl script included in the Bioperl package to obtain the set of GO slim associations for the clones on the array.

Clones corresponding to the same gene were grouped together. Counts of arrayed genes associated with each GO term and GO slim term were obtained. Representative GO slim terms were selected for inclusion in pie charts. Where GO slim terms were very broad (i.e. applied to a very large proportion of genes), they were excluded in favour of their more specific daughter terms. Conversely, where parent terms had large numbers of daughter terms, each with a small number of associated genes, the parent terms were included and the daughter terms excluded.

\section{Experiment 3}

\section{Embryo production and RNA isolation}

Day 7 blastocysts were produced from a total of nine replicates for both in vivo- and in vitro-cultured blastocysts as described in experiment 2 and stored, in pools of 10 , at $-80^{\circ} \mathrm{C}$ until use. RNA was extracted as described above and cDNA was synthesized using SuperScript III Rnase $\mathrm{H}^{-}$reverse transcriptase (catalogue number 18080044; Invitrogen) leaving a final volume of $40 \mu \mathrm{l}$.

Q-RT-PCR analyses were conducted as for experiment 1 on 23 genes of interest, selected on the basis of the lowest $P$ value calculated from the combined microarray data analyses. Between 3 and 6 replicates (different ovary collection days) per gene were used in the Q-RT-PCR validation of differential gene expression between in vivo- and 
in vitro-cultured blastocysts using bovine histone $\mathrm{H} 2 \mathrm{AZ}$ as the housekeeping gene. Primer sequences and the gene bank accession numbers of the genes examined are shown in Table 1.

Q-RT-PCR data $\left(C_{\mathrm{t}}\right.$ values) were analysed using the $2^{-\Delta \Delta C_{t}}$ method (Livak \& Schmittgen 2001) to determine the relative level of expression of each mRNA transcript in each sample. Differences in efficiency of cDNA production were corrected for by adjusting expression values ( $C_{t}$ values) of each mRNA according to corresponding H2AZ control/housekeeping gene expression values $\left(C_{t}\right.$ values). The relative abundance of the mRNAs between the two populations was calculated by dividing the in vivo-cultured blastocyst expression value by the in vitrocultured blastocyst expression (baseline) value, after $\mathrm{H} 2 \mathrm{AZ}$ correction, to [Q5] give a fold change value. Relative mRNA expression values for in vivo- and in vitro-cultured blastocysts were compared using Student's $t$ test. Samples were measured in duplicate for each gene of interest, and $\mathrm{H} 2 \mathrm{AZ}$ was measured in all samples in every 96-well plate that was subjected to Q-RT-PCR.

\section{Results}

\section{Experiment 1.Effects of amplification on relative gene expression differences}

When comparing the expression pattern of the same gene (e.g. ferritin) in two different samples (two-cell-stage embryos and blastocysts) the comparative level of expression varied, going from unamplified sample, to one round or two rounds of amplification; however, the relationship between the two samples remained the same, i.e. the level of ferritin transcript abundance was always lower in two-cell embryos compared with day 8 blastocysts (Fig. 1). Results were similar for $\beta$-actin expression (Fig. 2).

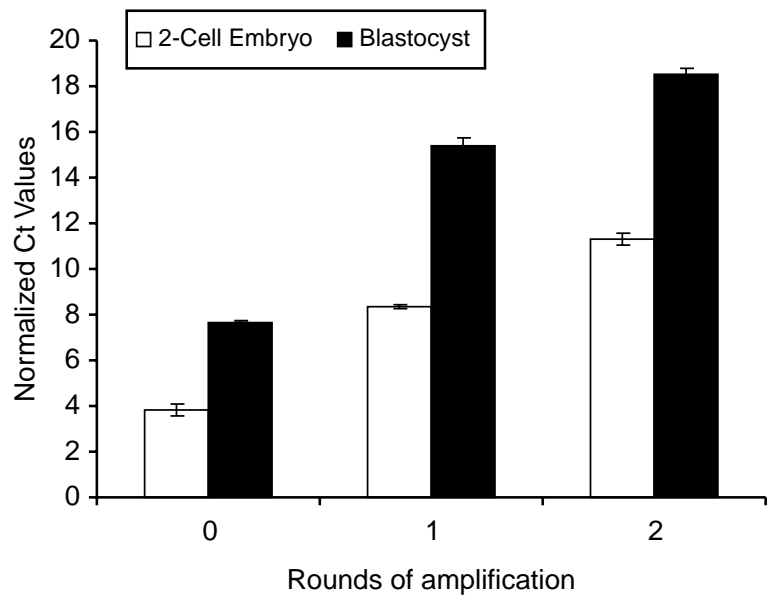

Figure 1 Effect of linear amplification on the relative expression level of ferritin in two-cell embryos compared with blastocysts.

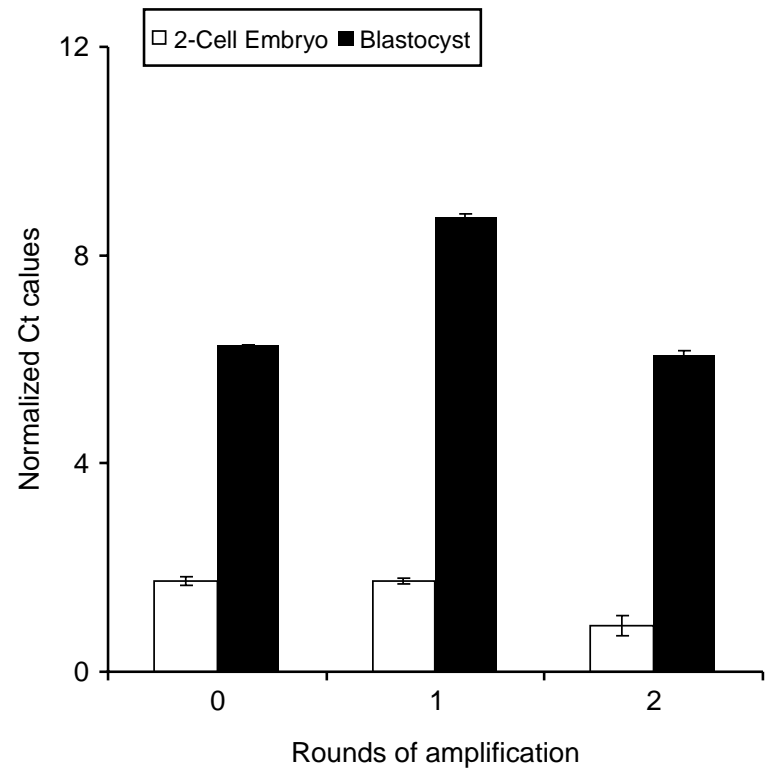

Figure 2 Effect of linear amplification on the relative expression level of $\beta$-actin in two-cell embryos compared with blastocysts.

\section{Experiment 2}

A total of 384 genes/ESTs were identified as putatively differentially expressed between the two sample types. The results of the ontology analysis of the differentially expressed genes are shown in Fig. 3. The distribution of these differentially expressed genes across the ontology categories did not differ from the overall distribution of genes on the array. Irrespective of the method of data analysis, the vast majority (approximately 85\%) of differentially expressed genes had a reduced expression in in vitro-cultured embryos compared with in vivo-cultured embryos.

\section{Experiment 3}

Q-RT-PCR was carried out using primers for 19 different genes and 4 ESTs, the Genbank accession numbers and primer sequences of which are shown in Table 1 (see Table 1 for abbreviations). Of the 23 transcripts indicated to be differentially expressed in experiment 2, $16(70 \%)$ were verified by RT-PCR to be differentially expressed $(P<0.05)$. Of the genes identified, 7 are involved in transcription and translation (CCR4-NOT, EEF1G, PABPN1, FOXO3A, HMG2, GNB2L1, DOT1L), 2 genes encode or interact with receptors (GCGR, REA) and 3 others encode factors involved in cellular metabolism (GALE, BiKKbeta, HEBP1). The 4 ESTs have similarity to genes involved in transcription, translation and receptors (3XC10R, 13_A08, 9_G06) or have unknown function (6XE03R).

All genes verified as being differentially expressed following Q-RT-PCR had higher expression levels in in vivocultured blastocysts compared with in vitro-cultured blastocysts (Fig. 4) ranging from a 1.40- (6XE03R) to a 6.94- (bIKK beta) fold difference in expression levels. 


\begin{tabular}{|c|c|}
\hline Molecular Function & $\begin{array}{l}\square \text { Protein binding } \\
\square \text { Signal transducer activity } \\
\square \text { Catalytic or enzyme regulator activity } \\
\square \text { Nucleic acid or nucleotide binding } \\
\text { — Transcription and translation regulator } \\
\square \text { Structural molecule } \\
\square \text { Transporter activity } \\
\square \text { Enzyme regulator activity } \\
\square \text { Others } \\
\square \text { Unknown Function }\end{array}$ \\
\hline
\end{tabular}

Figure 3 Ontology classifications of genes identified as being differentially expressed using DNA microarray in in vivocompared with in vitro-cultured blastocysts. Some genes are represented in more than one ontology.

\section{Discussion}

The data presented here are put in a biological context that potentially explains, at least in part, deficiencies contributing to reduced quality of in vitro-produced embryos. Microarray analysis identified 384 genes that differ in expression between in vivo- and in vitro-cultured blastocysts, $85 \%$ of which are underexpressed in in vitro-cultured embryos. RT-PCR on 23 of the most differentially expressed transcripts confirmed down-regulation of 12 genes and 4 ESTs, the majority of which have not been previously characterized in mammalian embryos. Interestingly, 10 of these genes are involved in transcription and translation and we suggest this deficiency compromises the quality of in vitro-cultured embryos.

One of the major limiting factors to characterising the global pattern of gene expression in embryos is the limited amount of embryonic RNA available for analysis. Bovine

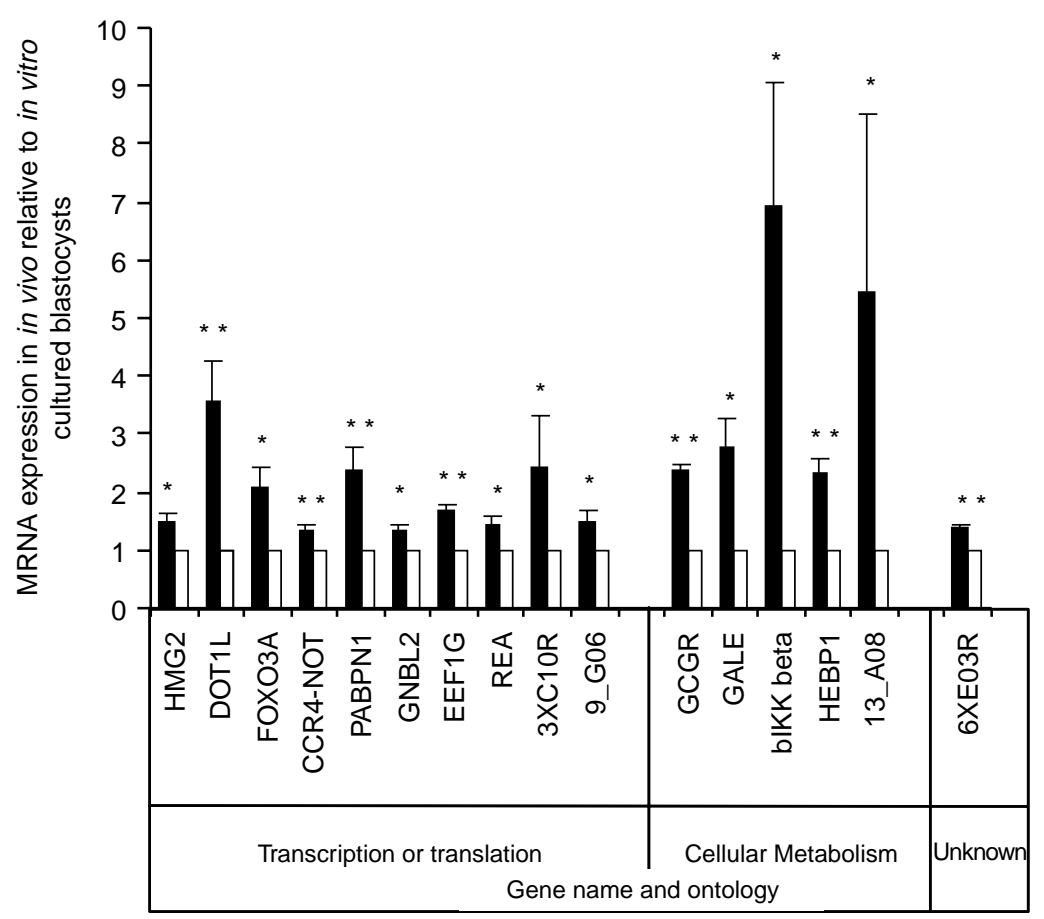

Figure 4 Level of gene expression in in vivo-cultured embryos (filled columns) relative to in vitro-cultured embryos (open columns) determined using Q-RT-PCR. $* P<0.05 ; * * P<0.01$. See Table 1 for full names of abbreviated genes. 
blastocysts contain approximately $5.3 \mathrm{ng}$ total RNA (Bilodeau-Goeseels \& Schultz 1997) with a ratio of mRNA to total RNA of about 3.5\% (Roozemond 1976, Piko \& Clegg 1982). Despite the fact that 50 blastocysts were pooled per biological replicate (giving approximately $9.3 \mathrm{ng} \mathrm{mRNA}$ ) this was still insufficient RNA for microarray analysis, where quantities in the microgram range are generally used. Linear amplification was used because it has been shown to introduce minimal disruption of mRNA expression patterns (Wang et al. 2000, Gomes et al. 2003, Jenson et al. 2003). We recently examined the fidelity of differential gene expression generated from unamplified versus amplified RNA from the same homogenous starting pools of bovine material using DNA microarrays; the hybridization intensities for each of the spots examined per slide for experiments using amplified versus non-amplified RNA were highly correlated $(\mathrm{R}$ squared $=0.86)$ and the false-positive rate was not affected (Patel et al. 2005). Data from the present study (experiment 1) showed that while the fold difference between the same genes in different samples (two-cell embryo and blastocyst) increased as the number of amplifications increased, the expression relationship between the samples was maintained (i.e. if the relative abundance of a transcript was higher in one group before amplification, it remained higher in that group following amplification).

A key factor that facilitates basic cell functioning and thereby embryonic development is the cell's ability to transcribe its DNA to single-stranded RNA and then translate the coding region nucleotide sequence of mRNA into the sequence of amino acids comprising a protein, with tRNA and rRNA providing the apparatus for protein synthesis. Here we have identified seven genes that are involved in transcription and translation, and that may have a crucial role in early embryo development. High mobility group protein 2 (HMG2) is a DNA-binding protein involved in bending DNA for critical steps in DNA replication, transcription and recombination (Fan et al. 2002). HMG proteins are a family of chromosomal proteins which act as structural elements of the chromatin and which promote transcription by modifying chromatin conformation (Bianchi \& Beltrame 2000, Vigneault et al. 2004). Members of the HMG protein family have previously been shown to be expressed throughout oocyte and early bovine development from the germinal vesicle stage to the blastocyst stage in in vitro-produced embryos (Vigneault et al. 2004). We have also identified the gene for DOT1L protein that is involved in the process of histone methylation, which is important in regulating chromatin dynamics and gene expression (Kouzarides 2002). DOT1L is an histone 3 lysine 79 (H3- K79)-specific methyltransferase and although the function of K79 methylation of histones is unknown, it is suggested that DOT1L regulates telomeric silencing through methylation of this lysine residue (Feng et al. 2002). FOXO3A, also known as FKHR-L1, is a member of the FOXO family of Forkhead transcription factors and is regulated by the
phosphoinositide-3-kinase-protein-kinase-B pathway. A number of studies have shown Forkhead transcription factors to have important roles in cell cycle arrest, apoptosis and stress responses in vitro (Medema et al. 2000, Burgering \& Kops 2002, Hosaka et al. 2004) and transcriptional control of key metabolic enzymes (O'Brien et al. 2001). Its role in reproduction is demonstrated by the fact that FOXO3A-null female mice show age-dependent infertility and abnormal ovarian follicular development (Hosaka et al. 2004). The expression of FOXO3A has not been previously described in embryos and the higher relative abundance of FOXO3A in vivo- compared with in vitroderived embryos in the present study suggests a role for this family of genes in mammalian embryo development. For the first time we have shown that the gene for CCR4NOT is more highly expressed in in vivo- compared with in vitro-cultured embryos (Fig. 4). The CCR4-NOT complex of proteins is central to the regulation of mRNA metabolism. It is involved in several aspects of mRNA formation, including repression and activation of mRNA initiation, control of mRNA elongation and the deadenylation and subsequent degradation of mRNAs (Denis \& Chen 2003).

Poly(A) tails are found at the $3^{\prime}$ ends of almost all eukaryotic mRNAs. They are bound by two different poly(A)-binding proteins, PABPC in the cytoplasm and PABPN1 in the nucleus. PABPN1, which displayed greater mRNA abundance in in vivo-cultured blastocysts, is involved in the synthesis of poly(A) tails, increasing the processivity of poly $(\mathrm{A})$ polymerase and contributing to defining the length of a newly synthesized poly $(\mathrm{A})$ tail (Kuhn \& Wahle 2004). The extent of the poly(A) tail at the $3^{\prime}$ end of mRNA transcripts is an important regulatory element for determining their stability and control of translation and we have previously demonstrated a clear relationship between the polyadenylation status of certain transcripts and bovine embryo developmental competence (Brevini-Gandolfi et al. 2000).

The guanine nucleotide-binding protein gene (GNB2L) is more highly expressed in in vivo- compared with in vitro-cultured embryos and encodes a receptor for activated C-kinase (RACK1) protein (Wang et al. 2003) which recruits activated protein kinase $C$ to the ribosome. This leads to the stimulation of translation through the phosphorylation of initiation factor 6 and, potentially, of mRNA-associated proteins. RACK1 therefore links signal transduction pathways directly to the ribosome, which allows translation to be regulated in response to cell stimuli (Nilsson et al. 2004). The relative higher abundance of GNBL2 transcripts in in vivo-cultured blastocysts compared with in vitro-cultured blastocysts may infer a superior translational mechanism in those embryos cultured in vivo compared with in vitro.

Elongation factor 1 gamma (EEF1G) is a nucleic acidbinding protein and is responsible for the enzymatic delivery of aminoacyl tRNAs to ribosomes. The tRNA carries the amino acid to the ribosome, which is then used in 
protein synthesis thereby inferring a crucial role for EEF1G in the translation process in protein biosynthesis. This is the first time that expression of this gene has been identified in bovine embryos. Greater abundance of this transcript in in vivo-cultured blastocysts as evidenced here may be important for de novo synthesis of proteins and consequently embryo development. Finally, the unknown EST, 9_G06 has weak similarity to a translation initiation factor in Saccharomyces cerevisae and may play an important role in the steps of protein synthesis via transcription and translation in early developing embryos.

In addition to the genes above that directly modulate transcription and translation, we have identified two genes that are more highly expressed in in vivo- compared with in vitro- cultured embryos whose products indirectly regulate transcription. The repressor of estrogen receptor activity (REA) is a co-regulator that directly interacts with the estrogen receptor and represses its transcriptional activity. Homozygous REA gene knockout mice do not develop past the embryonic day 9 stage of development, implying a critical role for REA in early development (Park et al. 2005). While the EST 3 XC10R has no convincing similarity with other known genes, it does have $74 \%$ sequence homology to human nuclear receptor co-activator 6 interacting protein (NCOA6IP). The protein encoded by this gene is a transcriptional co-activator that interacts with nuclear hormone receptors to enhance their transcriptional activator functions. Since 8 (and possibly 10, including EST-only genes) of the 16 genes that we have identified as being differentially expressed in in vivo- compared with in vitro-cultured embryos are associated with transcription and translation, we suggest that the apparent inability (or at least inefficiency) of the transcription-translation machinery to operate properly in in vitro- compared with in vivo-produced embryos is a major factor in contributing to the phenotypic differences between embryos developing in these two culture environments. In support of this notion, while the expression of connexin 43 (Cx43) transcripts, a gap junction protein involved in cell-to-cell communication, decreased in both in vivo- and in vitro-cultured embryos between the zygote and 8- to 16-cell stage; levels remained low thereafter in the in vitro-cultured embryos but increased significantly in those cultured in vivo, such that by the blastocyst stage there was a 10-fold difference in transcript abundance between embryos derived from the two culture environments (Lonergan et al. 2003b).

In addition to a number of transcription and translation factors, mentioned above, we have identified a number of genes that are involved in cellular metabolism and processes, and that are more highly expressed in in vivo- than in vitro-cultured embryos. These genes are the glucagon receptor (GCGR), UDP-galactose 4'-epimerase (GALE), IkB kinase-beta (bIKK-beta), a heme-binding protein and an EST with homology to an adenosine receptor. Glucagon is a key hormone in the regulation of glucose concentrations; its effects are mediated via a membrane receptor to stimulate an increase in CAMP via $G$ proteins and in turn stimulate protein kinase $\mathrm{A}$ (PKA) to phosphorylate many target proteins (Dean \& McEntyre 2004). Another gene more highly expressed in in vivo- compared with in vitro-cultured embryos encodes for heme-binding protein 1 (HEBP1). Heme is an iron and protein complex that serves as the prosthetic group of numerous hemoproteins (e.g. hemoglobin, myoglobin, cytochromes, guanylate cyclase and nitric oxide synthase) and plays an important role in controlling protein synthesis and cell differentiation (Ponka 1999). Heme-binding proteins may enhance, decrease or completely inhibit heme-catalyzed oxidations (Vincent et al. 1988) and we suggest that they are important for successful embryo development. Another gene that is up-regulated in in vivo- compared with in vitro-cultured embryos is blKK-beta, which is involved in the activation of an inhibitor of NF-к $\beta$ kinase (IKK). Activation of the IKK complex is a crucial step in NF-к $\beta$ signalling, which in turn has a critical role in the regulation and coordination of a wide range of cellular events such as cell growth, apoptosis and cell differentiation (Rottenberg et al. 2002). Another enzyme that is more highly expressed in in vivo- than in vitro-cultured embryos and that is involved in metabolism is UDP-galactose $4^{\prime}$-epimerase (GALE). GALE functions to interconvert UDP-galactose and UDP-glucose in the final step of the Leloir pathway of galactose metabolism; impairment of human GALE results in the metabolic disorder epimerase-deficiency galactosemia (Walter et al. 1999). Finally we have identified two ESTs that are more highly expressed in in vivo-than in vitro-cultured embryos. The EST 6XE03R has no homology with any previously described gene and the EST 13_A08 has no good sequence homology to other genes but it is moderately similar $(74.4 \%)$ to the adenosine $\mathrm{A} 2 \mathrm{~B}$ receptor (Canis familiaris). Adenosine, as well as being a building block of many biologically relevant molecules such as ATP and nucleic acids, is an endogenous nucleoside that regulates many physiological processes through the activation of any of its four G-protein-coupled receptor types (Ohta \& Sitkovsky 2001). Hence, we have identified five genes that are involved in signalling pathways and/or cellular processes - including metabolism, growth, apoptosis and differentiation - that we suggest are critical factors in determining the success of blastocyst development.

In summary, we have identified 12 genes and 4 ESTs (all except one have not been previously described in embryos) that we suggest are potentially critical in determining the quality of the blastocyst. The majority of these genes (10 of the 16) are involved in the regulation of transcription and translation which are vital processes for the cellular growth and division that is characteristic of embryos during the early stages of development. In vitro-cultured embryos are less developmentally competent than in vivo-cultured embryos. The suggestion that this is associated with a deficiency in genes controlling transcription in in vitro-cultured embryos is further supported by our finding using microarray analysis that $85 \%$ 
of the differentially expressed genes had lower expression in in vitro- than in vivo-cultured embryos, showing that the overall level of transcription in in vitro-cultured embryos may be much reduced compared with in vivo-cultured embryos. This theory is supported by results from a study on gene expression following culture of mouse embryos in vitro compared with in vivo: the majority of those transcripts that were found to be differentially expressed following culture in vitro compared with in vivo, were down-regulated in the in vitro-cultured embryos (Rinaudo \& Schultz 2004).

Understanding the molecular mechanisms underlying the reduced quality of in vitro-produced embryos could provide important insights into strategies for overcoming these deficiencies. Moreover, successful strategies could have far-reaching implications, not only for in vitro fertilization procedures in several species - including humans - but also for optimising other related technologies such as nuclear transfer induced reprogramming and stem cell procedures.

\section{Acknowledgements}

The authors declare that there is no conflict of interest that would prejudice the impartiality of this scientific work.

\section{References}

Abd El Razek IM, Charpigny G, Kodja S, Marquant-Le Guienne B, Mermillod P, Guyader-Joly C \& Humblot P 2000 Differences in lipid composition between in vivo- and in vitro-produced bovine embryos. Theriogenology 53346.

Ball PJH 1997 Late embryo and early fetal mortality in the cow. Animal Breeding Abstracts 65 167-175.

Bianchi ME \& Beltrame M 2000 Upwardly mobile proteins. Workshop: the role of HMG proteins in chromatin structure, gene expression and neoplasia. EMBO Report 1 109-114.

Bilodeau-Goeseels S \& Schultz GA 1997 Changes in ribosomal ribonucleic acid content within in vitro-produced bovine embryos. Biology of Reproduction 56 1323-1329.

Boni R, Tosti E, Roviello S \& Dale B 1999 Intracellular communication in in vivo- and in vitro-produced bovine embryos. Biology of Reproduction 61 1050-1055.

Brevini-Gandolfi T, Favetta LA, Lonergan P \& Gandolfi F 2000 The mechanism regulating maternal mRNA stability and translation is affected in bovine embryos with low developmental competence. Theriogenology 53268.

Burgering BM \& Kops GJ 2002 Cell cycle and death control: long live Forkheads. Trends in Biochemical Science 27 352-360.

Cleveland W \& Grosse E 1991 Computational methods of local regression. Statistics and Computing 1 47-62.

Crosier AE, Farin PW, Dykstra MJ, Alexander JE \& Farin CE 2000 Ultrastructural morphometry of bovine compact morulae produced in vivo or in vitro. Biology of Reproduction 62 1459-1465.

Crosier AE, Farin PW, Dykstra MJ, Alexander JE \& Farin CE 2001 Ultrastructural morphometry of bovine blastocysts produced in vivo or in vitro. Biology of Reproduction 64 1375-1385.

Crosier AE, Farin CE, Rodriguez KF, Blondin P, Alexander JE \& Farin PW 2002 Development of skeletal muscle and expression of candidate genes in bovine fetuses from embryos produced in vivo or in vitro. Biology of Reproduction 67 401-408.

Dean L \& McEntyre J 2004 In The Genetic Landscape of Diabetes. www.ncbi.nlm.nih.gov/books/.
Denis CL \& Chen J 2003 The CCR4-NOT complex plays diverse roles in mRNA metabolism. Progress in Nucleic Acid Research and Molecular Biology 73 221-250.

Duby RT, Hill JL, O'Callaghan D, Overstrom EW \& Boland MP 1997 Changes induced in the bovine zona pellucida by ovine and bovine oviducts. Theriogenology 47332.

Edmonds D, Lindsay K, Miller J, Williamson E \& Wood P 1982 Early embryonic mortality in women. Fertility and Sterility 38 447-453.

Enright BP, Lonergan P, Dinnyes A, Fair T, Ward FA, Yang X \& Boland MP 2000 Culture of in vitro produced bovine zygotes in vitro vs in vivo: implications for early embryo development and quality. Theriogenology 54 659-673.

Evans AC, Ireland JL, Winn ME, Lonergan P, Smith GW, Coussens PM \& Ireland JJ 2004 Identification of genes involved in apoptosis and dominant follicle development during follicular waves in cattle. Biology of Reproduction 70 1475-1484.

Fair T, Lonergan P, Dinnyes A, Cottell D, Hyttel P, Ward FA \& Boland MP 2001 Ultrastructure of bovine blastocysts following cryopreservation: effect of method of embryo production on blastocyst quality. Molecular Reproduction and Development $\mathbf{5 8}$ 186-195.

Fan Z, Beresford PJ, Zhang D \& Lieberman J 2002 HMG2 interacts with the nucleosome assembly protein SET and is a target of the cytotoxic T-lymphocyte protease granzyme A. Molecular Cell Biology 22 2810-2820.

Feng $\mathbf{Q}$, Wang $\mathrm{H}, \mathrm{Ng} \mathrm{HH}$, Erdjument-Bromage $\mathrm{H}$, Tempst $\mathrm{P}$, Struhl $\mathrm{K}$ \& Zhang Y 2002 Methylation of H3-lysine 79 is mediated by a new family of HMTases without a SET domain. Current Biology 12 $1052-1058$.

Galli C \& Lazzari G 1996 Practical aspects of IVM/IVF in cattle. Animal Reproduction Science 42 371-379.

Gomes LI, Silva RL, Stolf BS, Cristo EB, Hirata R, Soares FA, Reis LF, Neves EJ \& Carvalho AF 2003 Comparative analysis of amplified and nonamplified RNA for hybridization in CDNA microarray. Analytical Biochemistry 321 244-251.

Hasler JF, Henderson WB, Hurtgen PJ, Jin ZQ, McCauley AD, Mower SA, Neely B, Shuey LS, Stokes JE \& Trimmer SA 1995 Production, freezing and transfer of bovine IVF embryos and subsequent calving results. Theriogenology 43 141-152.

Hosaka T, Biggs WH 3rd, Tieu D, Boyer AD, Varki NM, Cavenee WK \& Arden KC 2004 Disruption of forkhead transcription factor (FOXO) family members in mice reveals their functional diversification. PNAS 101 2975-2980.

Jenson SD, Robetorye RS, Bohling SD, Schumacher JA, Morgan JW, Lim MS \& Elenitoba-Johnson KS 2003 Validation of cDNA microarray gene expression data obtained from linearly amplified RNA. Molecular Pathology 56 307-312.

Jeong YJ, Choi HW, Shin HS, Cui XS, Kim NH, Gerton GL \& Jun JH 2005 Optimization of real time RT-PCR methods for the analysis of gene expression in mouse eggs and preimplantation embryos. Molecular Reproduction and Development 71 284-289.

Khurana NK \& Niemann H 2000 Energy metabolism in preimplantation bovine embryos derived in vitro or in vivo. Biology of Reproduction 62 847-856.

Kouzarides T 2002 Histone methylation in transcriptional control. Current Opinions in Genetic Development 12 198-209.

Kuhn U \& Wahle E 2004 Structure and function of poly(A) binding proteins. Biochimica et Biophysica Acta 1678 67-84.

Lazzari G, Wrenzycki C, Herrmann D, Duchi R, Kruip T, Niemann H \& Galli C 2002 Cellular and molecular deviations in bovine in vitro-produced embryos are related to the large offspring syndrome. Biology of Reproduction 67 767-775.

Livak KJ \& Schmittgen TD 2001 Analysis of relative gene expression data using real-time quantitative PCR and the $2^{-\Delta \Delta C T}$ method. Methods 25 402-408.

Lonergan P, Rizos D, Gutierrez-Adan A, Fair T \& Boland MP 2003 a Oocyte and embryo quality: effect of origin, culture conditions and gene expression patterns. Reproduction in Domestic Animals 38 259-267. 
Lonergan P, Rizos D, Gutierrez-Adan A, Moreira PM, Pintado B, de la Fuente $\mathbf{J} \&$ Boland MP 2003b Temporal divergence in the pattern of messenger RNA expression in bovine embryos cultured from the zygote to blastocyst stage in vitro or in vivo. Biology of Reproduction 69 1424-1431.

Lonergan P, Pedersen HG, Rizos D, Greve T, Thomsen PD, Fair T, Evans A \& Boland MP 2004 Effect of the post-fertilization culture environment on the incidence of chromosome aberrations in bovine blastocysts. Biology of Reproduction 71 1096-1100.

Medema RH, Kops GJ, Bos JL \& Burgering BM 2000 AFX-like Forkhead transcription factors mediate cell-cycle regulation by Ras and PKB through p27kip1. Nature 404 782-787.

Memili E \& First NL 2000 Zygotic and embryonic gene expression in cow: a review of timing and mechanisms of early gene expression as compared with other species. Zygote 8 87-96.

Nilsson J, Sengupta J, Frank J \& Nissen P 2004 Regulation of eukaryotic translation by the RACK1 protein: a platform for signalling molecules on the ribosome. EMBO Reports 5 1137-1141.

O'Brien RM, Streeper RS, Ayala JE, Stadelmaier BT \& Hornbuckle LA 2001 Insulin-regulated gene expression. Biochemical Society Transactions $29552-558$.

Ohta A \& Sitkovsky M 2001 Role of G-protein-coupled adenosine receptors in downregulation of inflammation and protection from tissue damage. Nature 414 916-920.

Park SE, Xu J, Frolova A, Liao L, O'Malley BW \& Katzenellenbogen BS 2005 Genetic deletion of the repressor of estrogen receptor activity (REA) enhances the response to estrogen in target tissues in vivo. Molecular and Cellular Biology 25 1989-1999.

Patel OV, Suchyta SP, Sipkovsky SS, Yao J, Ireland JJ, Coussens PM \& Smith GW 2005 Validation and application of a high fidelity mRNA linear amplification procedure for profiling gene expression. Veterinary Immunology and Immunopathology 105 331-342.

Peters AR 1996 Embryo mortality in the cow. Animal Breeding Abstracts 64 587-598.

Piko L \& Clegg KB 1982 Quantitative changes in total RNA, total poly(A), and ribosomes in early mouse embryos. Developmental Biology $89362-378$.

Pollard JW \& Leibo SP 1994 Chilling sensitivity of mammalian embryos. Theriogenology 41 101-106.

Ponka P 1999 Cell biology of heme. American Journal of Medical Science $318241-256$.

Rinaudo P \& Schultz RM 2004 Effects of embryo culture on global pattern of gene expression in preimplantation mouse embryos. Reproduction $128301-311$.

Rizos D, Lonergan P, Ward F, Duffy P \& Boland MP 2002a Consequences of bovine oocyte maturation, fertilization or early embryo development in vitro versus in vivo: implications for blastocyst yield and blastocyst quality. Molecular Reproduction and Development 61 234-248.

Rizos D, Fair T, Papadopoulos S, Boland MP \& Lonergan P $2002 b$ Developmental, qualitative, and ultrastructural differences between ovine and bovine embryos produced in vivo or in vitro. Molecular Reproduction and Development 62 320-327.

Rizos D, Lonergan P, Boland MP, Arroyo-Garcia R, Pintado B, de la Fuente J \& Gutierrez-Adan A 2002c Analysis of differential messenger RNA expression between bovine blastocysts produced in different culture systems: implications for blastocyst quality. Biology of Reproduction 66 589-595.
Rizos D, Gutierrez-Adan A, Perez-Garnelo S, De La Fuente J, Boland MP \& Lonergan P 2003 Bovine embryo culture in the presence or absence of serum: implications for blastocyst development, cryotolerance, and messenger RNA expression. Biology of Reproduction 68 236-243.

Roozemond RC 1976 Ultramicrochemical determination of nucleic acids in individual cells using the Zeiss UMSP-I microspectrophotometer. Application to isolated rat hepatocytes of different ploidy classes. Histochemistry Journal 8 625-638.

Rottenberg S, Schmuckli-Maurer J, Grimm S, Heussler VT \& Dobbelaere DA 2002 Characterization of the bovine IкB kinases $(\mathrm{IKK}) \alpha$ and IKK $\beta$, the regulatory subunit NEMO and their substrate ІкB $\alpha$. Gene $299293-300$.

Sreenan J, Diskin M \& Morris D 2001 Embryo survival rate in cattle: a major limitation to the achievement of high fertility. In Fertility in the High-Yielding Dairy Cow, pp 93-104. BSAS Occasional Publication 26, Scotland, UK: British Society of Animal Science.

Tesfaye D, Ponsuksili S, Wimmers K, Gilles M \& Schellander K 2004 A comparative expression analysis of gene transcripts in post-fertilization developmental stages of bovine embryos produced in vitro or in vivo. Reproduction in Domestic Animals 39 396-404.

Thompson JG 2000 In vitro culture and embryo metabolism of cattle and sheep embryos - a decade of achievement. Animal Reproductive Science 60-61 263-275.

Vigneault C, McGraw S, Massicotte L \& Sirard MA 2004 Transcription factor expression patterns in bovine in vitro-derived embryos prior to maternal-zygotic transition. Biology of Reproduction $\mathbf{7 0}$ 1701-1709.

Vincent S, Grady R, Shaklai N, Snider J \& Muller-Eberhard U 1988 The influence of heme-binding proteins in heme-catalyzed oxidations. Archives of Biochemistry and Biophysics 265 539-550.

Viuff D, Rickords L, Offenberg H, Hyttel P, Avery B, Greve T, Olsaker I, Williams JL, Callesen H \& Thomsen PD 1999 A high proportion of bovine blastocysts produced in vitro are mixoploid. Biology of Reproduction 60 1273-1278.

Walter JH, Roberts RE, Besley GT, Wraith JE, Cleary MA, Holton JB \& MacFaul R 1999 Generalised uridine diphosphate galactose-4-epimerase deficiency. Archives of Diseases in Childhood 80 374-376.

Wang E, Miller LD, Ohnmacht GA, Liu ET \& Marincola FM 2000 High-fidelity mRNA amplification for gene profiling. Nature Biotechnology 18 457-459.

Wang S, Chen J, Zhang Z, Gu S, Ji C, Tang R, Ying K, Xie Y \& Mao Y 2003 Cloning, expression and genomic structure of a novel human GNB2L1 gene, which encodes a receptor of activated protein kinase C (RACK). Molecular Biology Report 30 53-60.

Wrenzycki C, Herrmann D, Lucas-Hahn A, Korsawe K, Lemme E \& Niemann H 2005 Messenger RNA expression patterns in bovine embryos derived from in vitro procedures and their implications for development. Reproduction, Fertility and Development 17 23-35.

Received 22 October 2005

First decision 22 November 2005

Revised manuscript received 2 January 2006

Accepted 16 January 2006 